\title{
Safety of Epidural Steroid Injection Methods in the Management of Recurrent Lumbar Disc Herniation: Few Comments
}

\author{
Mohamed Amin Ghobadifar ${ }^{1}$, Farideh Pourghardash ${ }^{2}$, Armin Akbarzadeh ${ }^{3}$, Zahra Mosallanejad ${ }^{4}$ \\ ${ }^{1}$ Zoonoses Research Center, Jahrom University of Medical Sciences, Jahrom, Iran \\ ${ }^{2}$ Research Center for Social Determinants of Health, Jahrom University of Medical Sciences, Jahrom, Iran \\ ${ }^{3}$ Health Policy Research Center, Shiraz University of Medical Sciences, Shiraz, and \\ Student Research Committee, Shiraz University of Medical Sciences, Shiraz, Iran \\ ${ }^{4}$ Department of Gynecology and Obstetrics, Shiraz University of Medical Sciences, Shiraz, Iran
}

Dear Editor,

We were recently interested by an article published in the Asian Spinal Journal by Karamouzian et al. [1], entitled "Comparison of two methods of epidural steroid injection in the treatment of recurrent lumbar disc herniation". The authors presented an intriguing investigation comparing the effectiveness of the different methods of epidural steroid injection (ESI) in patients with recurrent lumbar disc herniation, and reported similar outcomes of transforaminal and caudal steroid injection procedures in the treatment of lumbar disc herniation. Although caudal and transforminal steroid injections are the commonly performed techniques in the management of the pain of disc herniation, the results are unsatisfactory, given the certain unique risks carried by ESI procedures. To Karamouzian et al. discussion, we also note the risks and complications of ESIs in the spine, which is evident in the results discussed below.

Some studies in the literature showed that ESIs is no better or even worse than a placebo. It is also observed that ESIs is often implicated in permanent and severe complications such as spinal cord infarction, infection, intravascular injections, injections into the spinal fluid, nerve damage, hemorrhages, paralysis, weakening the disc or leading to discitis and archnoiditis [2,3]. Moreover, transforminal steroid injection technique does not decrease the risk of known complications of interlaminar steroid injection procedure, including hematoma formation, subdural and dural punctures, and cauda-equina syndrome [4].

Also, Manchikanti et al. [5] in a prospective, nonrandomized study of patients undergoing ESIs observed complications including intravascular injection, local bleeding, oozing, and local hematoma with profuse bleeding. Other reports [6,7] indicated that ESIs provided no additional improvements and no significant functional benefits or reduction in the need for surgery.

As is obvious from the above discussion, although ESI approaches are commonly performed techniques in the management of the pain of disc herniation, complications and pitfalls of ESIs should be assessed to alter and add

Received Dec 11, 2014; Accepted Dec 12, 2014

Corresponding author: Mohamed Amin Ghobadifar

Zoonoses Research Center, Medicine School, Jahrom University of Medical Sciences,

Motahari Avenue, Jahrom, Iran Post code: 193

Tel: +98-936-620-8078, Fax: +98-711-636-13-86, E-mail: amin_m505@yahoo.com 
more consistency to the results.

\section{Conflict of Interest}

No potential conflict of interest relevant to this article was reported.

\section{References}

1. Karamouzian S, Ebrahimi-Nejad A, Shahsavarani S, Keikhosravi E, Shahba M, Ebrahimi F. Comparison of two methods of epidural steroid injection in the treatment of recurrent lumbar disc herniation. Asian Spine J 2014;8:646-52.

2. Chang Chien GC, Candido KD, Knezevic NN. Digital subtraction angiography does not reliably prevent paraplegia associated with lumbar transforaminal epidural steroid injection. Pain Physician 2012;15:515-23.
3. Cohen SP, Maine DN, Shockey SM, Kudchadkar S, Griffith S. Inadvertent disk injection during transforaminal epidural steroid injection: steps for prevention and management. Pain Med 2008;9:688-94.

4. Bilir A, Gulec S. Cauda equina syndrome after epidural steroid injection: a case report. J Manipulative Physiol Ther 2006;29:492.e1-3.

5. Manchikanti L, Malla Y, Wargo BW, Cash KA, Pampati V, Fellows B. Complications of fluoroscopically directed facet joint nerve blocks: a prospective evaluation of 7,500 episodes with 43,000 nerve blocks. Pain Physician 2012;15:E143-50.

6. Valat JP, Giraudeau B, Rozenberg S, et al. Epidural corticosteroid injections for sciatica: a randomised, double blind, controlled clinical trial. Ann Rheum Dis 2003;62:639-43.

7. Carette S, Leclaire R, Marcoux S, et al. Epidural corticosteroid injections for sciatica due to herniated nucleus pulposus. N Engl J Med 1997;336:1634-40. 